
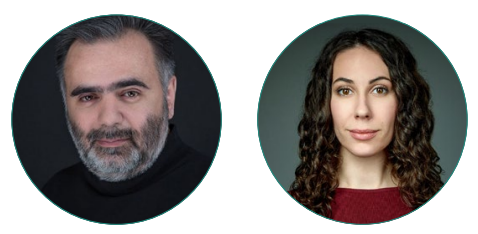

В. А. Черный, В. В. Вебер

\title{
АВТОРСКИЕ ПЛАТФОРМЫ - ГЛАВНЫЙ ТРЕНД В РАЗВИТИИ СОЦИАЛЬНЫХ СЕТЕЙ
}

\section{Правильная ссылка на статью:}

Черный В.А., Вебер В.В. Авторские платформы-главный тренд в развитии социальных сетей // Мониторинг общественного мнения: экономические и социальные перемены. 2021. № 5. С. 192-198. https://doi.org/10.14515/monitoring.2021.5.2101.

\section{For citation:}

Cherny V. A., Veber V.V. (2021) Author Platforms as a Key Trend in the Development of Social Networks. Monitoring of Public Opinion: Economic and Social Changes. No. 5. P. 192-198. https://doi.org/10.14515/monitoring.2021.5.2101. (In Russ.) 
АВТОРСКИЕ ПЛАТФОРМЫ-ГЛАВНЫЙ ТРЕНД В РАЗВИТИИ СОЦИАЛЬНЫХ СЕТЕЙ

ЧЕРНЫЙ Василий Анатольевич - директор по маркетингу, «ПалитрумЛаб" (Brand Analytics), Москва, Россия E-MAIL: vcherny2003@gmail.com https://orcid.org/0000-0002-1377-7631

ВЕБЕР Валерия Вячеславовна - бакалавр, ведущий маркетолог, «ПалитрумЛаб” (Brand Analytics), Москва, Россия E-MAIL: veberlera@gmail.com https://orcid.org/0000-0001-8985-4106

Аннотация. В рамках статьи рассматриваются данные регулярного исследования активной аудитории социальных сетей в России за октябрь 2020 г. В исследование включены данные по социальным сетям "ВКонтакте", Instagram, "Одноклассники", Facebook, YouTube, Twitter, TikTok, включающие объем аудитории, возраст и пол авторов. Внимание исследования сосредоточено на активной (пишущей) аудитории - социальные сети изучаются как средство публичной коммуникации, влияющее на общественное мнение. Для выделения данных по стране по каждой соцсети учтен процент геоопределения: количество сообщений, у которых имеются данные по географии, поделено на процент сообщений с геоданными. Аналогично для авторов.

В результате исследования выявлены социальные сети с наибольшим ростом активной аудитории за 2020 г.: Instagram, YouTube и TikTok. Сформулированы тренды их развития. Для них проведен анализ и составлен рейтинг наиболее вовлекающих в коммуника-

\section{AUTHOR PLATFORMS AS A KEY TREND IN THE DEVELOPMENT OF SOCIAL NETWORKS}

Vasily A. CHERNY ${ }^{1}$ - Marketing Director E-MAIL: vcherny2003@gmail.com https://orcid.org/0000-0002-1377-7631

Valeria V. VEBER ${ }^{1}$ - Bachelor Degree, Lead Marketing Specialist

E-MAIL: veberlera@gmail.com https://orcid.org/0000-0001-8985-4106

1 “PalitrumLab” (Brand Analytics), Moscow, Russia

Abstract. The article investigates the data from a regular study of an active audience of social networks in Russia for October 2020. We analyze data on social networks VKontakte, Instagram, Odnoklassniki, Facebook, YouTube, Twitter, TikTok. The data includes audience size, age and gender of authors. We focus on an active (writing) audience, exploring social media as a means of public communication that influences public opinion. To isolate data by country for each social network, we consider the percentage of geo-identification: we divide the number of posts with geographic data by the percentage of posts with geodata. Likewise, for authors.

As a result, we identified social networks with the highest growth in active audience in 2020 - Instagram, YouTube and TikTok - and formulated their development trends. We analyzed and ranked the authors most engaging in communication, interpreting engagement as the sum of likes, reposts and comments in the author's account for September 2021. For the top three fastest growing 
цию авторов. Вовлеченность - сумма лайков, репостов и комментариев в аккаунте автора за сентябрь 2021 г. Для тройки быстрорастущих соцсетей проанализирован контент трех самых популярных авторов.

Ключевые слова: социальные сети, анализ соцсетей, социальные медиа, аналитика соцмедиа, медиапотребление, TikTok, Instagram, YouTube social networks, we analyzed the content of the three most popular authors.

Keywords: social networks, social network analysis, social media, social media analitics, media consuption, TikTok, Instagram, YouTube

Селебрити в социальных сетях или селебрити социальных сетей? Такая постановка вопроса уже не слишком актуальна. Многие из звезд офлайна и классических медиа давно и успешно "живут" в социальных сетях. А авторы, вырастившие миллионные аудитории на социальных платформах, сами давно уже стали звездами.

Популярность в социальных сетях стала универсальным мерилом успеха. Социальным капиталом, который может быть легко конвертирован. Например, в финансовый успех. Именно поэтому журнал Forbes с 2019 г. в рейтинге самых успешных звезд шоу-бизнеса и спорта стал учитывать их востребованность в социальных медиа ${ }^{1}$.

Мы обсудим тренды в развитии социальных сетей в России в 2020-2021 гг. Остановимся подробнее на популярных авторах и трендах самых быстрорастущих социальных платформ.

\section{Социальные сети России. Числа и тренды 2020/2021}

Пандемия преподала нам ускоренный курс цифровизации, и социальные медиа в этот момент оказались в лидерах роста. Под социальными медиа принято понимать любые онлайн-площадки, где пользователи могут оставить свое мнение. Это не только соцсети. Это блоги, форумы, отзовики, геосервисы, сторы, маркетплейсы, видеохостинги, UGC-ресурсы и т.д.

Согласно исследованию Brand Analytics «Социальные сети России, осень 2020. Цифры и Тренды” ${ }^{2}$, число активных авторов соцмедиа за год выросло на $30 \%-$ с 49 до 64 млн. Активные авторы - это авторы, которые хотя бы один раз в месяц проявили в соцсетях активность написанием поста, комментария или репостом. Лидерами роста по объему активной аудитории в 2020 г. стали Instagram, YouTube и TikTok - социальные платформы, ориентированные на распространение и потребление авторского контента скорее, чем на общение пользователей между собой, как это устроено в соцсетях "все в одном".

- Instagram в 2020 г. продемонстрировал впечатляющий рост с 27,7 млн до 42,8 млн авторов и вышел на первое место в России по активной аудитории.

\footnotetext{
1 Рейтинг Forbes: “Самые успешные звезды шоу-бизнеса и спорта моложе 40 лет»; Рейтинг Brand Analytics для Forbes: «Популярность звезд в социальных медиа".

2 Исследование Brand Analytics: “Социальные сети в России, осень 2020. Цифры и Тренды».
} 
- YouTube за этот же период вырос более чем в 10 раз - до 7,7 млн активных авторов и обошел по этому показателю "Одноклассники", став в России соцсетью № 3 после Instagram и «ВКонтакте».

- TikTok по активной аудитории приблизился на "опасное расстояние" к "Одноклассникам", а по объему публикуемого контента обогнал YouTube.

При этом общий объем ежемесячно публикуемого в соцмедиа контента не вырос - это по-прежнему примерно 1,2 млрд публикаций. По этому показателю традиционно и с большим перевесом лидирует "ВКонтакте" - в этой соцсети пользователи публикуют вдвое больше сообщений, чем в Instagram,- - почти 0,5 млрд публикаций в месяц. Второе место у Instagram - 265 млн публикаций, третье у "Одноклассников" - 108 млн (см. рис. 1).

Рис. 1. Социальные медиа в России. Основные характеристики, 2020 г.

\section{Социальные медиа в России}

Сообщений в месяц

1,2 млрд

Соообений в месяц, млн.

ВКонтакте

Instagram

Одноклассники *

Facebook

Twitter

Tiktok

Youtube

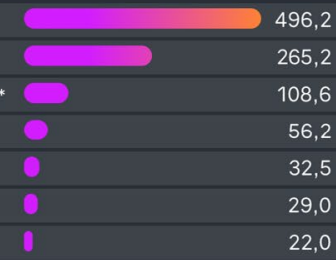

22,0
Авторов в месяц

\section{$64 \mathrm{M}$}

Авторов в месяц, млн.

Instagram

ВКонтакте

Youtube

Одноклассники

Tiktok

Facebook

Twitter

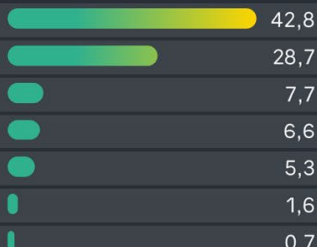

0,7

Основные термины исследования

Автор - пользователь, написавший хотя бы 1 публичное сообщение за месяц

Сообщение - любой открытый (публичный) пост, включая комментарии.

Россия, октябрь 2020

Подготовлено Brand Analytics, системой анализа соцмедиа и СМИ

Главный тренд 2020 и 2021 гг.- универсальные соцсети "все в одном" для общения проигрывают в росте социальным платформам с авторским контентом - "соцсетям-телевизорам", сделавшим ставку на простоту механики, мобильные приложения, мультимедийные форматы фото, видео и сторис, встроенные спецэффекты, а также на рекомендательные алгоритмы. Посмотреть любимых блогеров, поучиться, поразвлечься, “потупить" - вот актуальный пользовательский сценарий "отбросить все лишнее».

Если изначально в соцсети приходили за общением, то сейчас пользователи все чаще потребляют создаваемый профессиональными блогерами контент - все как на диване у телевизора. Наблюдается расслоение аудитории - кто-то подался в блогеры, а кто-то переместился в зрительский зал. В быстро растущих авторских социальных платформах более 80 \% пользователей только комментируют чужой контент, но не публикуют собственный. А $20 \%$ составляют как раз активные авторы (блогеры). Это и есть новые звезды. 
Давайте посмотрим на лидеров популярных социальных медиа. Представленные рейтинги составлены на основании показателя вовлеченности - сумме лайков, репостов и комментариев в аккаунте автора за месяц. Такие данные демонстрируют реальный интерес пользователей к автору и его контенту.

\section{TikTok}

В сентябре 2021 г. самые вовлекающие блогеры TikTok ${ }^{3}$ :

1 место - XO Team

2 место - Yolo House;

3 место-i_am_doshik;

Пользователи переключают внимание с соло-блогеров на мультиавторство: в рейтинге сразу четыре аккаунта дуэтов и два творческих объединения авторов. TikTok-хаусы укрепляют свои позиции в рейтинге: второй месяц подряд лидирующую позицию рейтинга занимают аккаунты творческих объединений. В сентябре 201 X0 Team стал самым вовлекающим аккаунтом августа, получив 81 млн реакций. На этой позиции аккаунт потеснил YOLO House, который оказался самых популярным в августе этого года. Популярность авторам обеспечивает «народность" контента - большинство видео ориентированы на мультикультурных пользователей и не имеют привязки к региону или языку. Благодаря этому у блогеров большое комьюнити фанатов в странах Юго-Восточной Азии и США.

Сегодня блогеры осознают свое влияние и стараются использовать популярность на благо: набирают популярность социально ответственные челленджи. Один из таких проходит с хештегом \#мамасказалаэтонормально, где пользователи рассказывают, как научились принимать свои особенности вопреки давлению окружающих.

Еще один тренд платформы - переход на commerce-подход. Вместе с расширением промо-возможностей на платформу пришли рекламодатели, которые предлагают молодым инфлюенсерам рекламные бюджеты уровня телевидения.

В таких условиях конкуренция среди TikTok-блогеров за внимание пользователей и рекламодателей нешуточная: блогеры снимают по пять-шесть роликов в день, устраивают масштабные коллаборации и используют профессиональный продакшен, чтобы сделать максимально вовлекающий контент.

Лайки выступают самой "легкой" валютой внимания в TikTok, требуя от пользователя минимального вовлечения. Однако лайки-основа уровня вовлеченности, которая составляет более $90 \%$ от суммарного показателя. По количеству комментариев у автора можно судить о степени лояльности пользователей к автору. Пользователи ценят свое время на платформе и готовы идти в комментарии только под выборочными видео, которые находят живой отклик у аудитории и стимулируют поделиться своим мнением.

\section{Instagram}

Топ-3 популярных русскоязычных аккаунтов Instagram в сентябре 2021 г. составили:

\footnotetext{
3 Топ-50 блогеров в TikTok по вовлеченности, сентябрь 2021//Brand Analytics. 2021. URL: https://br-analytics.ru/ mediatrends/authors/tiktok/ (дата обращения: 31.10.2021).
} 
1 место - Khabib Nurmagomedov;

2 место - Goar Avatisyan;

3 место - Настя Ивлеева.

Позиции блогеров в Instagram гораздо стабильнее - из месяца в месяц самыми популярными оказываются одни и тех же селебрити, меняя лишь позицию в рейтинге. Блогерская сфера в Instagram сформировалась достаточно давно, поэтому лидирующие позиции у блогеров здесь стабильнее, чем в TikTok: юным блогерам редко удается набрать вовлеченность более 10 млн реакций за месяц.

При этом конкуренция в Instagram как никогда высокая: блогеры одновременно сражаются не только за внимание пользователя, но и за внимание алгоритмов соцсети. Количество подписчиков уже не "решает" - валютой в Instagram стала вовлеченность, она же главная метрика для рекламодателей и брендов, планирующих эффективное сотрудничество с инфлюенсером.

Рейтинг демонстрирует тренд на "мультипопулярность" участников топа. Фанатов объединяет желание наблюдать за своими кумирами с разных ракурсов: по этой причине популярный на одной площадке блогер с легкостью набирает подписчиков в другой соцсети. Если блогер известен в TikTok или YouTube, то и в Instagram миллион подписчиков он набирает быстро. И наоборот - инстаграмеры с легкостью «залетают" В тренды на видеоплатформах. В топ-20 представлены авторы, чья популярность имеет кросс-платформенный характер. Это Аня Покров, Валя Карнавал, Instasamka.

\section{YouTube}

В топ-5 русскоязычных блогеров YouTube ${ }^{4}$ с наиболее вовлекающим контентом за сентябрь 2021 г. входят:

1 место - Влад Бумага (А4);

2 место - EdisonPts;

3 место - FixEye.

Среди участников рейтинга традиционно лидируют летсплееры (пользователи, транслирующие в прямом эфире прохождение игры) и обзорщики игр. Тренд на завоевание YouTube летсплеерами, который Brand Analytics констатировал еще в феврале 2019 г., ${ }^{5}$ вновь актуален. Этот популярный сегмент русскоязычного YouTube сформировал собственную замкнутую экосистему со своими кумирами, которые периодически меняют позиции в рейтинге, но крайне редко покидают его.

Все чаще можно услышать, что YouTube становится заменой телевидению. Сразу три новостных канала вошли в топ-30: высокую вовлеченность показали телеканал "Дождь", "Россия 24" и "Матч ТВ". Такой тренд уже отмечался в декабре 2020 г., когда телеканалы были на нижних позициях рейтинга, но показывали перспективу роста.

\footnotetext{
4 Рейтинг авторов и групп. Источник - ҮouTube, сентябрь 2021//Brand Analytics. URL: https://br-analytics.ru/ mediatrends/authors/youtube/ (дата обращения: 31.10.2021).

5 Топ-20 русскоязычных уoutube-блогеров, февраль 2019. "Немного политики и много летсплееров и челленджеров" // Brand Analytics. 2019. 18 марта. URL: https://br-analytics.ru/blog/top-20-youtube-blogerov/ (дата обращения: 31.10.2021).
} 


\section{Заключение}

Представленные данные наглядно показывают наиболее динамичный сегмент социальных медиа - авторские социальные платформы с визуальным контентом: Instagram, YouTube и TikTok. Аудиторию последних можно разделить на создателей контента (блогеры) и зрителей (комментируют чужой контент, но не создают свой). Блогеров на указанных платформах - примерно $20 \%$, комментаторов - примерно $80 \%$.

В связи с быстрым ростом указанных платформ представляется интересным и важным регулярно изучать и рейтинговать их активных авторов для отслеживания трендов и новых сценариев взаимодействия социальных платформ и пользователей. 